\title{
Retired Concept
}

National Cancer Institute

\section{Source}

National Cancer Institute. Retired Concept. NCI Thesaurus. Code C28428.

Concept has been retired, and should not be used except to deal with old data. 